\title{
Comportamento de cordeiros em pastejo de azevém (Lolium multiflorum) em diferentes fases fenológicas submetidos à adubação nitrogenada
}

\begin{abstract}
Luiz Giovani de Pellegrini ${ }^{1}$, Alda Lúcia Gomes Monteiro², Mikael Neumann ${ }^{3}$, Paulo César de Faccio Carvalho ${ }^{4}$, Ana Luisa Palhano Silva ${ }^{5}$, Sebastião Brasil Campos Lustosa ${ }^{3}$, Ana Carolina Ribeiro Sanquetta de Pellegrin ${ }^{6}$
\end{abstract}

\begin{abstract}
RESUMO
O objetivo deste trabalho foi avaliar o efeito de nitrogênio (N) em pastagem de azevém (Lolium multiflorum Lam.), manejada à mesma altura em pastejo contínuo, sobre o comportamento ingestivo de cordeiros de corte. Utilizaram-se o azevém com quatro doses de N, empregando-se ureia comercial (45\% de N) com aplicação única, sendo: 0 kg/ha de N; $75 \mathrm{~kg} / \mathrm{ha}$ de N; $150 \mathrm{~kg} / \mathrm{ha}$ de N; e $225 \mathrm{~kg} / \mathrm{ha}$ de N. O período de avaliação foi de 63 dias, dividido em três períodos de 21 , que corresponderam aos estágios de desenvolvimento das plantas desde a fase vegetativa até o florescimento. Em cada período os dias foram divididos em três turnos de avaliação comportamental: manhã (6:30 às 10:30), meio-dia (10:31 às 14:30) e tarde (14:31 às 18:30). Na análise dos períodos, os animais diminuíram a atividade de ócio em 0,3 min a cada dia de avanço no ciclo da pastagem, independentemente do turno de avaliação. Já para o consumo de água, não houve diferença entre as fases fenológicas (média de 1,8 min por dia). Os cordeiros reduziram o tempo de ruminação em 0,612; 0,660; e 0,060 min a cada dia de utilização da pastagem nos turnos da manhã (6:30 - 10:30), meio-dia (10:31 14:30) e tarde (14:31 - 18:30), respectivamente, ao passo que para o pastejo os tempos destinados a essa atividade aumentaram 0,$726 ; 1,104 ;$ e 0,354 min, respectivamente. Com relação às doses de $\mathrm{N}$, não houve interferência $(\mathrm{P}>0,05)$ sobre as atividades de ruminação (126,6 $\mathrm{min})$ e consumo de água (10,5 min). Observou-se comportamento linear crescente $(\mathrm{P}<0,05)$ para ócio em 0,108 min e decrescente para pastejo em 0,198 min para cada kg de $\mathrm{N}$ aplicado na pastagem. O estágio fenológico do azevém influenciou as atividades comportamentais dos cordeiros.
\end{abstract}

Palavras-chave: Ovinos, ócio, pastejo, ruminação, ureia.

\section{ABSTRACT \\ Behavior of lambs grazing in ryegrass (Lolium multiflorum) at different phenological stages subjected to nitrogen fertilization}

The aim of this work was to evaluate the effect of nitrogen $(\mathrm{N})$ levels on ryegrass pasture (Lolium multiflorum Lam), managed at the same pasture height under continuous grazing on the ingestive behavior of meat lambs. Four levels of nitrogen obtained from commercial urea ( $45 \%$ of $\mathrm{N}$ ) were applied in a single application: $0 \mathrm{~kg} / \mathrm{ha}$ of N; $75 \mathrm{~kg} / \mathrm{ha}$ of N; 150 $\mathrm{kg} / \mathrm{ha}$ of $\mathrm{N}$; and $225 \mathrm{~kg} / \mathrm{ha}$ of $\mathrm{N}$. Evaluations were performed during 63 days, divided into three periods of 21 days, corresponding to plant development stages from vegetative to reproductive stage. In each period, the days were

\footnotetext{
Recebido para publicação em abril de 2009 e aprovado em maio de 2011

${ }^{1}$ Médico Veterinário, Doutor. Universidade Estadual do Centro-Oeste, Departamento de Medicina Veterinária, Rua Simeão Camargo Varela de Sá, ${ }^{\circ} 3$, Bairro Cascavel, 85040080, Guarapuava, Paraná, Brasil. depellegrini@yahoo.com.br

${ }^{2}$ Engenheira-Agrônoma, Doutora. Universidade Federal do Paraná, Departamento de Zootecnia, Rua dos Funcionários, 1540, Bairro Juvevê, 80035-050, Curitiba, Paraná, Brasil. aldaufpr@gmail.com

${ }^{3}$ Engenheiro-Agrônomo, Doutor. Universidade Estadual do Centro-Oeste, Departamento de Medicina Veterinária, Rua Simeão Camargo Varela de Sá, ${ }^{\circ} 3$, Bairro Cascavel, 85040-080, Guarapuava, Paraná, Brasil. mikaelneumann@ hotmail.com

${ }^{4}$ Zootecnista, Doutor. Universidade Federal do Rio Grande do Sul, Departamento de Plantas Forrageiras, Av. Bento Gonçalves, 7712, Bairro Centro, 91540-000, Porto Alegre, Rio Grande do Sul, Brasil. paulocfc@ufrgs.br

${ }_{5}^{5}$ Engenheira-Agrônoma, Doutora. Departamento de Medicina Veterinária, Universidade Tuiuti do Paraná, Rua Tobias de Macedo Júnior, 333, Santo Inácio, 82010-340, Curitiba, Paraná,Brasil. aluisa@pop.com.br

${ }^{6}$ Medica Veterinária. Universidade Federal de Santa Maria, Programa de Pós-Graduação em Zootecnia, Camobi, 97105-900, Santa Maria, Rio Grande do Sul, Brasil.
}

Rev. Ceres, Viçosa, v. 58, n.3, p. 329-335, mai/jun, 2011 
divided into 3 evaluation shifts: morning (6:30 a.m. to 10:30 a.m.), noon (10:31 a.m. to 2:30 p.m.) and afternoon (2:31 p.m. to 6:30 p.m.). Lambs decreased idle time in 0.3 minutes each day of advancement in the pasture cycle, independent of the evaluation shift. However, for water consumption there was no difference $(\mathrm{P}>0.05)$ between the phenological phases (average of 1.8 minutes per day). Lambs decreased rumination time in $0.612 ; 0.660$ and 0.060 minutes for each day of pasture utilization in the morning (6:30 a.m.-10:30 a.m.), noon (10:31 a.m.-2:30 p.m.) and afternoon shifts (2:31 p.m.- 6:30 p.m.), respectively, while grazing activity increased $0.726 ; 1.104$ and 0.354 minutes, respectively. Nitrogen levels had no influence $(\mathrm{P}>0.05)$ on time of rumination (126.6 minutes) and water consumption (10.5 minutes). Nitrogen levels showed linear increase $(\mathrm{P}<0.05)$ for idle time of 0.108 minutes and linear decrease for grazing of 0.198 minutes for each $\mathrm{kg}$ of $\mathrm{N}$ applied to pasture. Phenological stage influenced lamb behavior activities.

Key words: Grazing, idle time, urea, rumination, sheep.

\section{INTRODUÇÃO}

Ecossistemas pastejados e manejados com diferentes doses de fertilizante nitrogenado podem condicionar distintas ofertas de forragem, em quantidade e qualidade, bem como diferentes estruturas do dossel. Isso pode influenciar o consumo de forragem e, de acordo com Stobbs (1975), determinar alterações no comportamento ingestivo de animais em pastejo.

A estrutura da pastagem é definida por Laca \& Lemaire (2002) como a distribuição e o arranjo da parte aérea das plantas numa comunidade. Para Carvalho et al. (2001), a estrutura da pastagem é a forma como a forragem está disponível ao animal. Os mesmos autores salientam que essa estrutura é uma característica central determinante tanto da dinâmica de crescimento e competição nas comunidades vegetais quanto do comportamento ingestivo dos animais e é responsável, em última análise, pela quantidade dos nutrientes ingeridos em pastejo.

A relação entre a vegetação e o pastejo é dinâmica, em que a estrutura e a qualidade da vegetação alteram a dieta dos herbívoros em pastejo, que, por sua vez, afetam a estrutura da pastagem. A estrutura da vegetação ainda é alterada em razão de outros fatores, entre eles a quantidade de nitrogênio (N) utilizado, em que é possível de se obterem estruturas distintas com a mesma altura de pastejo, dependendo da dose de $\mathrm{N}$ utilizada (Pellegrini et al., 2010a). Ainda as plantas presentes no dossel passam por sucessivos estádios de desenvolvimento com o avançar da idade, também alterando a estrutura da vegetação, o que leva os animais a utilizarem diferentes estratégias comportamentais, seja na busca do alimento, no consumo de água e na ruminação ou ócio (Pedroso et al., 2004).

Entretanto, não há informações de como essas estratégias de pastejo variam ao longo do mesmo período e ainda, quando a pastagem apresenta diferentes estrutura e qualidade nutricional determinadas por variação na quantidade de $\mathrm{N}$ utilizado e no estádio fenológico das plantas. Sendo assim, o objetivo deste trabalho foi verificar o efeito das doses de $\mathrm{N}$ em pastagem de azevém em diferentes fases fenológicas sobre o comportamento ingestivo de cordeiros de corte mantidos em pastejo contínuo.

\section{MATERIAL E MÉTODOS}

O experimento foi conduzido nas instalações do Núcleo de Produção Animal (NUPRAN) do Centro de Ciências Agrárias e Ambientais da Universidade Estadual do Centro Oeste (UNICENTRO), em Guarapuava-PR, no período de junho a novembro de 2006.

O clima da região de Guarapuava-PR é o Cfb (Subtropical mesotérmico úmido), sem estação seca, com verões frescos e inverno moderado, conforme a classificação de Köppen, em altitude de aproximadamente 1.100 $\mathrm{m}$, precipitação média anual de $1.944 \mathrm{~mm}$, temperatura média mínima anual de $12,7^{\circ} \mathrm{C}$, temperatura média máxima anual de $23,5^{\circ} \mathrm{C}$ e umidade relativa do ar de $77,9 \%$. O solo da área experimental, classificado como Latossolo Bruno Típico (Embrapa, 1999), em julho de 2006 apresentou as seguintes características químicas (perfil de 0 a $20 \mathrm{~cm}$ ): $\mathrm{pH} \mathrm{CaCl}_{20,01 \mathrm{M}}: 4,7 ; \mathrm{P}: 1,1 \mathrm{mg} \mathrm{dm}^{3-} ; \mathrm{K}^{+}: 0,2 \mathrm{cmol}_{\mathrm{c}} \mathrm{dm}^{3-} ; \mathrm{MO}$ : $2,62 \% ; \mathrm{Al}^{3+}: 0,0 \mathrm{cmol}_{\mathrm{c}} \mathrm{dm}^{3-} ; \mathrm{H}^{+}+\mathrm{Al}^{3+}: 5,2 \mathrm{cmol}_{\mathrm{c}} \mathrm{dm}^{3-} ; \mathrm{Ca}^{2+}$ : $5,0 \mathrm{cmol}_{\mathrm{c}} \mathrm{dm}^{3-} ; \mathrm{Mg}^{2+}: 5,0 \mathrm{cmol}_{\mathrm{c}} \mathrm{dm}^{3-}$; e saturação de bases: $67,3 \%$.

O pasto foi implantado em 6 de junho de 2006, em sistema de plantio direto, após aplicação do herbicida gliphosate (360 g/L). No plantio do azevém utilizou-se espaçamento entre linhas de $15 \mathrm{~cm}$, profundidade de semeadura de $0,4 \mathrm{~cm}$ e densidade de semeadura de $45 \mathrm{~kg}$ de sementes por ha.

Os tratamentos corresponderam a quatro doses de $\mathrm{N}$, na forma de ureia $(45 \%$ de N), sendo: $0 \mathrm{~kg} /$ ha de $\mathrm{N} ; 75 \mathrm{~kg}$ / ha de $\mathrm{N} ; 150 \mathrm{~kg} / \mathrm{ha}$ de $\mathrm{N}$; e $225 \mathrm{~kg} / \mathrm{ha}$ de N. A área total 
utilizada no experimento foi de 3,1 ha, em que: 0,5 ha foi destinado à manutenção de animais controladores e 2,6 ha foram subdivididos em três blocos de 0,88 ha cada, sendo cada bloco dividido em quatro piquetes (unidade experimental) com 0,22 ha em média cada.

Foi utilizada adubação de base de $300 \mathrm{~kg} / \mathrm{ha}$ com $0 \mathrm{~N}$, $60 \mathrm{~kg} / \mathrm{ha} \mathrm{P}_{2} \mathrm{O}_{5}$ e $60 \mathrm{~kg} / \mathrm{ha} \mathrm{K} \mathrm{O}_{2}$, conforme Comissão de Fertilidade de Solo (1995). Após 35 dias da semeadura (11 de julho de 2006), foi efetuada aplicação única da adubação nitrogenada de cobertura na forma de ureia, o que corresponde ao início do perfilhamento das plântulas.

Antes do começo do experimento, os animais tiveram seis dias de adaptação à dieta e às instalações experimentais e, na sequência, três períodos de 21 dias de avaliação do comportamento, totalizando 63 dias de experimento. $\mathrm{O}$ curto período de adaptação dos animais justifica-se pelo fato desses já estarem em pastejo em azevém na propriedade de origem.

Foram utilizados 72 cordeiros (as) desmamados, com idade média de dois meses e peso vivo inicial de $24,7 \mathrm{~kg} \pm$ $0,57 \mathrm{~kg}$. Os animais foram distribuídos aleatoriamente nos tratamentos de acordo com peso e sexo. Cada lote de animais constituiu-se de dois machos castrados, dois machos não castrados e duas fêmeas.

Os animais utilizados como reguladores foram provenientes de rebanhos de propriedades próximas do local de execução do experimento. Todos os animais que chegaram foram tratados para ecto e endoparasitas com ivermectina e pesados em jejum de sólidos de 14 horas, antes de entrarem na área experimental.

Os animais foram distribuídos em 12 lotes de seis cada, sendo mantidos em pasto de azevém em sistema de lotação contínua, em piquetes de 0,22 ha cada, com carga variável. A lotação contínua foi adotada por intermédio da técnica put-and-take (Moot \& Lucas, 1952), utilizando seis animais-testes e número variável de reguladores por piquetes, com o objetivo de manter a altura do pasto entre 14 e 15 cm, seguindo recomendações de Freitas (2003). Assim, os ajustes da lotação foram feitos periodicamente em intervalos de três dias, considerando a relação entre a altura e a massa de forragem, segundo Carvalho et al. (2001).

Para alcançar a altura de manejo pretendida, utilizouse, além dos animais-testes, 130 animais reguladores, que apresentavam a mesma idade e peso vivo médios, com o objetivo de não alterar o comportamento dos animais.

As observações do comportamento animal foram realizadas em cada unidade experimental (piquetes), em dois dias consecutivos do nascer $(6: 30)$ ao pôr do sol (18:30), em cada período de utilização da pastagem. As avaliações de comportamento foram realizadas durante os períodos (P) de avaliação, procurando-se acompanhar os estágios de desenvolvimento da pastagem: $\mathrm{P}_{1}=$ estágio vegetativo
(20/08 a 10/09); $\mathrm{P}_{2}=$ estágio pré-florescimento (11/09 a 01/ 10); e $\mathrm{P}_{3}=$ estágio de florescimento (02/10 a 22/10). Em cada avaliação o ciclo comportamental foi dividido em três turnos de avaliação: manhã (6:30 às 10:30), meio-dia (10:31 às 14:30) e tarde (14:31 às 18:30).

Para a avaliação do comportamento animal utilizaramse quatro animais-testes (dois machos castrados, um macho não castrado e uma fêmea), identificados com cores diferentes para que os observadores pudessem acompanhar as atividades individuais desses animais em distância superior a $5 \mathrm{~m}$. Foi utilizado um observador por unidade experimental, em sistema de revezamento. As leituras foram tomadas a intervalos regulares de seis minutos. Os resultados das avaliações do comportamento animal, representados pelas atividades de ócio, ruminação, ingestão de água e pastejo, foram expressos em minutos diurnos de atividade.

A taxa de bocados foi avaliada registrando-se o tempo gasto pelos animais para efetuar 20 bocados (Forbes \& Hodgson, 1985). Cabe esclarecer que o cronômetro não era parado caso o animal caminhasse com a cabeça baixa enquanto selecionava a forragem ou caso os animais levantassem a cabeça enquanto estivessem mastigando grande quantidade de forragem extraída de um bocado. Entretanto, se o animal levantasse sua cabeça e não recomeçasse a pastejar em menos de um minuto essa observação era desconsiderada (Gibb, 1998).

Para avaliar o tempo de procura pela estação alimentar, observou-se o tempo e o número de passos necessários à procura e utilização de 10 estações alimentares, de forma visual e semelhante ao procedimento para avaliação da taxa de bocados, considerando-se como estação alimentar toda e qualquer atividade de pastejo sem movimentação das patas dianteiras (Carvalho, 1997).

O delineamento experimental foi o de blocos ao acaso, com quatro tratamentos e três repetições, em que cada repetição era representada por um piquete, em esquema fatorial 4 x 3 , sendo quatro doses de nitrogênio e três turnos de comportamento animal. Os dados coletados para cada variável foram submetidos a análise de variância a $5 \%$ de significância, por intermédio do proc $\mathrm{glm}$, e os resultados significativos foram submetidos à análise de variância (proc reg) e ainda realizou-se a correlação (porc var) entre as variáveis por intermédio do programa estatístico SAS (1997).

A análise de cada variável seguiu o modelo estatístico: $\mathrm{Y}_{\mathrm{ijk}}=\mu+\mathrm{N}_{\mathrm{i}}+\mathrm{T}_{\mathrm{j}}+\left(\mathrm{N}^{*} \mathrm{~T}\right)_{\mathrm{ij}}+\mathrm{R}_{\mathrm{l}}\left(\mathrm{N}^{*} \mathrm{~T}\right)_{\mathrm{ij}}+\mathrm{P}_{\mathrm{k}}+(\mathrm{N} * \mathrm{P})_{\mathrm{ik}}+$ $(\mathrm{T} * \mathrm{P})_{\mathrm{jk}}+\mathrm{E}_{\mathrm{ijk}}$; em que: $\mathrm{Y}_{\mathrm{ijk}}=$ variáveis dependentes; $\mu=$ média geral de todas as observações; $\mathrm{N}_{\mathrm{i}}=$ efeito da dose de nitrogênio $(\mathrm{N})$ de ordem "i", sendo 1 = dose zero de $\mathrm{N}$, $2=$ dose 75 de N, $3=$ dose 150 de N e $4=$ dose 225 de N; $T_{j}$ $=$ turno do dia de ordem “j”, sendo $1=$ turno das $6: 30$ às $10: 31,2=$ turno das $10: 31$ às $14: 30$ e $3=$ turno das 14 : 
31 às $18: 30 ;\left(\mathrm{N}^{*} \mathrm{~T}\right)_{\mathrm{ij}}=$ efeito da interação entre a i-ésima dose de $\mathrm{N}$ com a j-ésima turno do dia; $\mathrm{R}_{1}\left(\mathrm{~N}^{*} \mathrm{~T}\right)_{\mathrm{ij}}=$ efeito aleatório baseado na repetição dentro da combinação $\left(\mathrm{N}^{*} \mathrm{~T}\right)_{\mathrm{ij}}\left(\right.$ Erro a); $\mathrm{P}_{\mathrm{k}}=$ efeito do estágio de desenvolvimento de ordem " $\mathrm{k}$ ", sendo 1 = estágio vegerativo, 2 = estágio pré-florecimento e 3 = estágio de florecimento; $(\mathrm{N} * \mathrm{P})_{\mathrm{ik}}=$ efeito da interação entre a i-ésima dose de $\mathrm{N}$ com a késima estágio de desenvolvimento; $\left(\mathrm{T}^{*} \mathrm{P}\right)_{\mathrm{jk}}=$ efeito da interação entre a j-ésima turno do dia com a k-ésima estágio de desenvolvimento; e $\mathrm{E}_{\mathrm{ijkl}}=$ efeito aleatório residual (Erro b). A interação $\left(\mathrm{N}^{*} \mathrm{~T}^{*} \mathrm{P}\right)_{\mathrm{ijk}}$ também foi inicialmente testada; no entanto, em razão da baixa magnitude, foi removida do modelo estatístico.

\section{RESULTADOS E DISCUSSÃO}

Não houve interação $(P>0,05)$ entre doses de nitrogênio, turno de avaliação e estágio de desenvolvimento da pastagem para todas as variáveis avaliadas. Observa-se que também não houve interação $(\mathrm{P}>0,05)$ entre turno de avaliação e estágio de desenvolvimento da pastagem para as atividades ócio e consumo de água, enquanto para as atividades de ruminação e pastejo houve interação significativa $(\mathrm{P}<0,05)$.

Quanto aos estágios de desenvolvimento, os animais diminuíram a atividade de ócio em 0,3 min a cada dia de avanço no ciclo da pastagem, independentemente do turno de avaliação do comportamento. Já para a atividade de consumo de água, não houve diferença $(\mathrm{P}>0,05)$ entre os estágios do ciclo, apresentando valor médio de 1,8 min de ingestão de água. Independentemente do estágio de desenvolvimento da pastagem, os cordeiros dedicaram maior tempo ao ócio (39 min) e consumo de água (2,4 min) no turno do meio dia, comparativamente aos turnos da manhã e da tarde, como já era esperado devido ao aumento normal de temperatura que ocorre nesse período do dia.

Comportamento observado neste experimento é explicado por Mayes \& Duncan (1986), os quais se referem que a organização temporal do pastejo pode apresentar várias refeições, as quais são interrompidas por intervalos de comprimento variado, que são destinados a outras atividades, como ócio e consumo de água. Ainda Silveira (2001) salienta que a atividade de pastejo concentra-se nos turnos da manhã e tarde e as atividades de ócio e consumo de água estão em maior proporção no período do meio-dia.

Com relação ao tempo de ruminação, os cordeiros reduziram em 0,612; 0,66; e 0,06 min a cada dia de utilização da pastagem nos turnos da manhã, meio-dia e tarde (Figura $1 \mathrm{~A}, 1 \mathrm{~B}$ e 1C), respectivamente, ao passo que os tempos destinados ao pastejo aumentaram em 0,726; 1,104; e 0,354 min por dia, conforme as equações de regressão apresentadas na Figura 2A, 2B e 2C.
Nesse sentido, o pastejo foi a atividade que ocupou maior parte do tempo dos cordeiros mantidos em pasto de azevém, esse percentual elevado, próximo a $64 \%$, pode ser explicado em parte pelo tempo de procura do alimento; ou seja, pela discriminação entre os componentes da pastagem quando há oportunidade de livre escolha (Polli et al., 2009). O maior tempo dedicado ao pastejo pelos cordeiros proporcionou menor período de ruminação e ócio, o que é explicado em razão das atividades dos animais serem excludentes, em que o aumento ou a redução no tempo de pastejo resulta em alteração nas demais atividades (Carvalho et al., 2001).

Corroborando com esses dados, Parente et al. (2005) encontraram maior tempo destinado ao pastejo nos ciclos
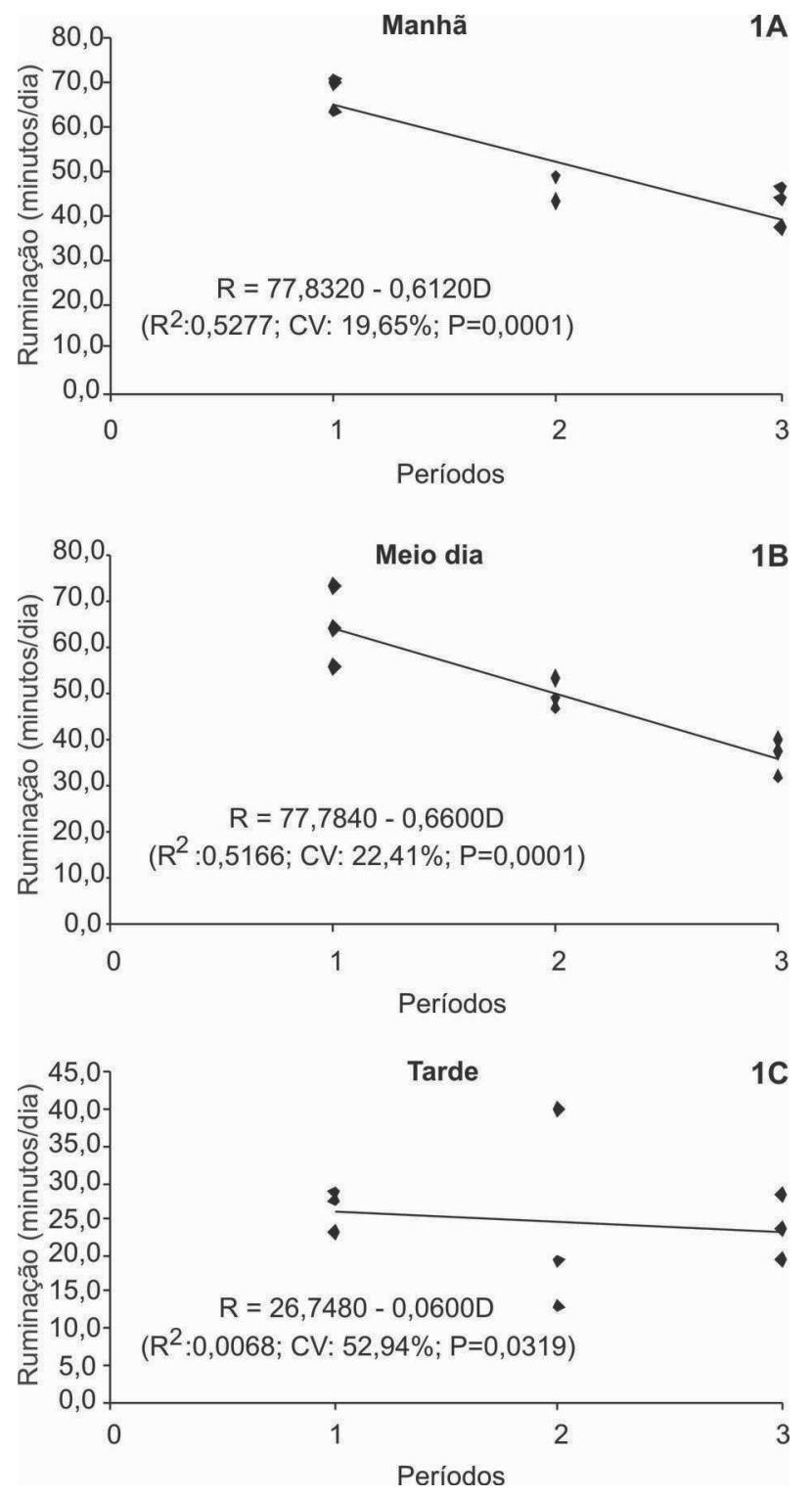

Figura 1. Comportamento de ruminação expresso em minutos de atividade diurna (6:30 - 18:30) dos cordeiros de corte em razão do turno diário e estágio de desenvolvimento da pastagem de azevém.

Rev. Ceres, Viçosa, v. 58, n.3, p. 329-335, mai/jun, 2011 
da manhã e tarde e para ócio próximo ao meio-dia, sendo este justificado por temperaturas mais elevadas.

No decorrer do ciclo das plantas da pastagem, diferentes estádios fonológicos, os cordeiros manifestaram comportamento linear nas atividades de ócio, ruminação e pastejo; ou seja, para cada dia de utilização da pastagem reduziram o período ócio e a ruminação em 0,9000 e 1,3320 min, respectivamente, e aumentou o tempo de pastejo em 2,1780 min (Figura 3A, 3B e 3C). O consumo de água foi variável, mostrando comportamento quadrático, com ponto de máxima ingestão aos 46,87 dias de utilização da pastagem (Figura 3D).

Esse comportamento também foi observado por Pedroso et al. (2004), tendo sido justificado pelo estágio
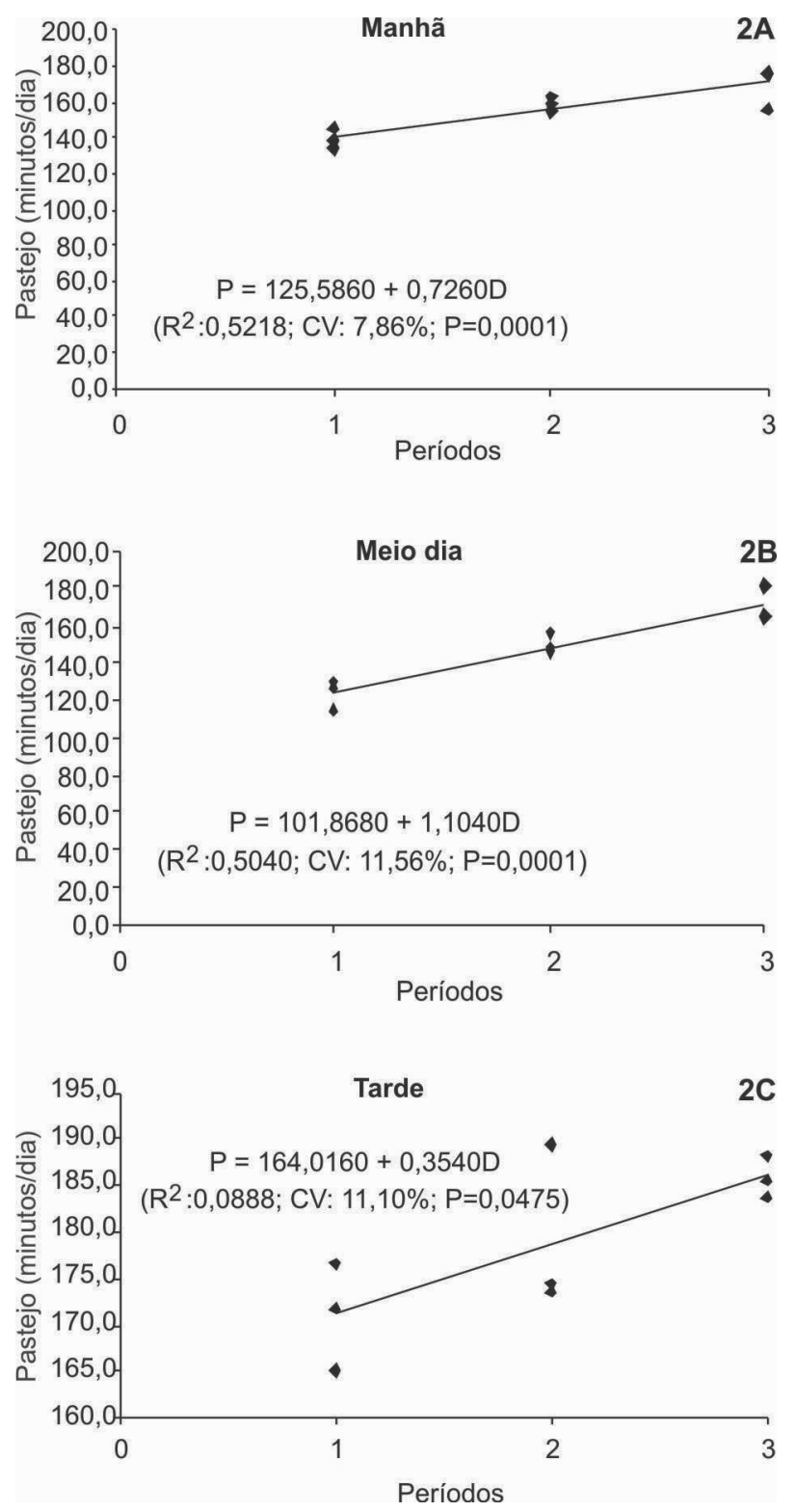

Figura 2. Comportamento de pastejo expresso em minutos de atividade diurna (6:30 - 18:30) dos cordeiros de corte em razão do turno diário e estágio de desenvolvimento da pastagem de azevém. de desenvolvimento em que se encontrava a pastagem. Os autores verificaram que o tempo de pastejo de 576,6 $\mathrm{min} /$ dia (estágio vegetativo) aumentou para 658,2 $\mathrm{min} /$ dia (pré-florecimento); ou seja, os ovinos necessitaram de maior tempo de pastejo para compensar a queda de qualidade da pastagem com o avanço do ciclo produtivo. As informações referentes à qualidade do pasto podem ser observadas no trabalho de Pellegrini et al. (2010a), em que a queda na qualidade é significativa com o avanço do período de sua utilização, justificando o comportamento dos dados obtidos.

O aumento no pastejo e a redução do ócio e ruminação ainda se justificam pela participação dos componentes estruturais do pasto, em que o componente folhas reduziu linearmente com o avanço do ciclo de utilização, sendo expresso pela equação de regressão $\mathrm{Y}=65,7208$ 0,6986D ( $\mathrm{R}^{2}$ : 0,8927; $\left.\mathrm{P}=0,0001\right)$ e o colmo apresentou comportamento quadrático, expresso pela equação $\mathrm{Y}=$ $26,2562+0,8618 \mathrm{D}-0,0107 \mathrm{D}^{2}\left(\mathrm{R}^{2}: 0,7393 ; \mathrm{P}=0,0001\right)$. Pedroso et al. (2004) obtiveram o mesmo comportamento e o justificou em razão dos componentes estruturais do pasto, que apresentaram comportamento semelhante ao ocorrido no presente experimento.

Medeiros et al. (2007) também observaram o mesmo comportamento, tendo eles afirmado que as mudanças na estrutura e na qualidade da forragem ofertada determinam mudanças comportamentais ao longo dos ciclos de pastejo; essa estratégia reflete a tentativa do animal em garantir a quantidade de forragem necessária ao longo do dia, o que, provavelmente, é consequência da maior competição pela forragem disponível, decorrente da maior presença de animais em atividade de pastejo em mesmo intervalo de tempo (Armstrong et al., 1995).

Não houve interação $(\mathrm{P}>0,05)$ entre doses de nitrogênio e estágio de desenvolvimento da pastagem para as variáveis relativas ao comportamento animal (Figuras 3 e 4). Houve efeito $(\mathrm{P}<0,05)$ das doses de nitrogênio para as atividades de pastejo e ócio; o mesmo não ocorreu (P > $0,05)$ para as de ruminação e consumo de água.

As atividades de ruminação e consumo de água apresentaram valores médios de 126,6 e 10,5 min no período diurno (6:30 - 18:30) de utilização da pastagem. No que se refere ao tempo em ócio, identificou-se comportamento linear crescente em 0,1080 min por $\mathrm{kg}$ de $\mathrm{N}$, enquanto para o pastejo o mesmo foi decrescente em 0,1980 min para cada kg de $\mathrm{N}$ aplicado na pastagem (Figura 4A e 4B).

Os ovinos respondem à diminuição da percentagem de folhas verdes disponíveis, aumentando o tempo que passam pastejando, tentando compensar a redução na qualidade da dieta, já que a acessibilidade de folhas e o grau de maturidade da planta estão intimamente relacionados com o valor nutritivo da pastagem. Essa estreita relação do consumo com a oferta e a acessibilidade das 

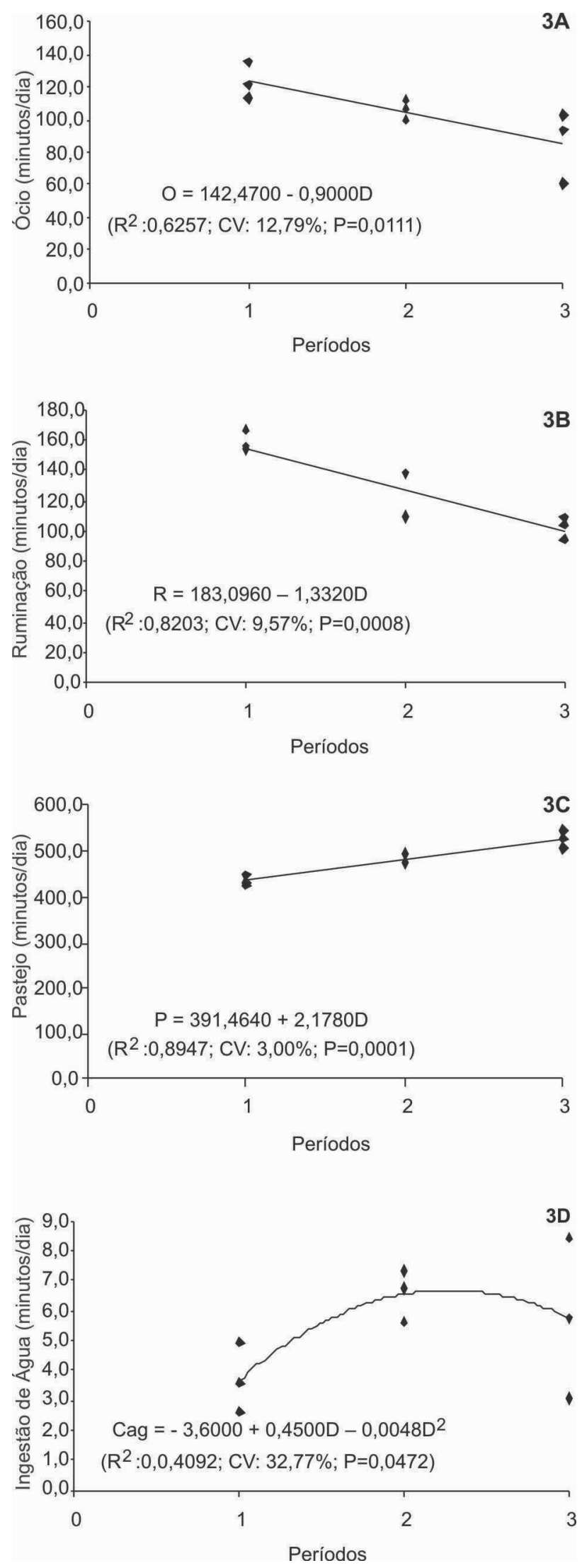

Figura 3. Comportamento animal, expresso em minutos de atividade diurna (6:30 - 18:30), em ócio, ruminação, pastejo e ingestão de água dos cordeiros de corte em pastagem de azevém em razão do estádio de desenvolvimento da pastagem de azevém. folhas verdes é amplamente comprovada na literatura (Barthram \& Grant, 1984; Forbs \& Coleman, 1993).

No presente experimento, o decréscimo no tempo de pastejo em resposta ao aumento de $\mathrm{N}$ foi provocado pela melhor relação folha:colmo da pastagem (Pellegrini et al. (2010a) à medida que a dose de $\mathrm{N}$ elevou-se, favorecendo o maior consumo de forragem de boa qualidade pelos cordeiros, representada pela equação $\mathrm{Y}=0,6605+0,0010 \mathrm{~N}$ ( $\mathrm{R}^{2}$ : 0,4390; $\mathrm{P}=0$,0189) (Pellegrini et al., 2010b). O maior consumo de folhas em relação aos colmos é também atribuído à maior digestão e ao menor tempo de retenção das folhas no rúmen (Pedroso et al., 2004), o que poderia sugerir menor tempo de ruminação para os cordeiros em pastagens com maior intensidade de uso do $\mathrm{N}$, embora no presente estudo esse efeito não tenha sido observado ( $\mathrm{P}$ $=0,1924)$.

Diferentemente dos resultados aqui encontrados com cordeiros desmamados, Freitas (2003) não constatou diferença para o tempo gasto com atividades diurnas de ovelhas e seus cordeiros, independentemente das doses
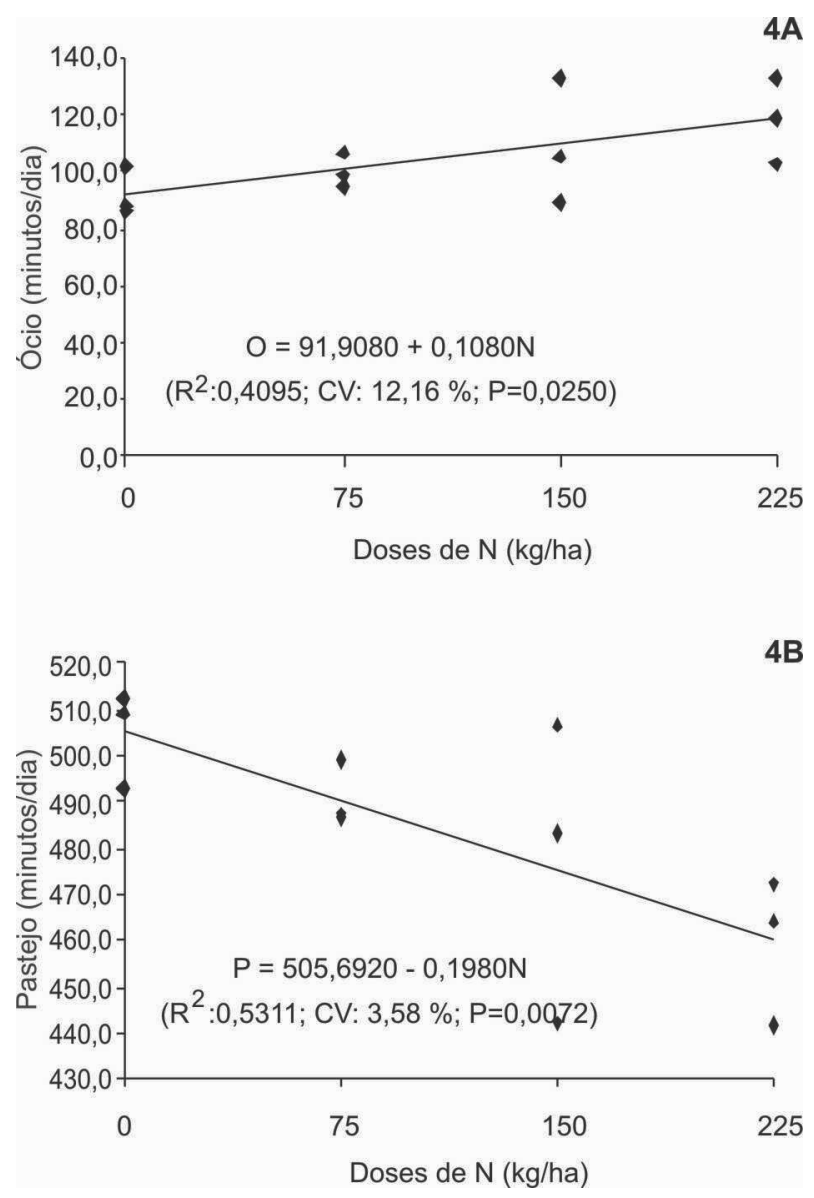

Figura 4. Comportamento animal, expresso em minutos de atividade diurna (6:30 -18:30), em ócio e pastejo de cordeiros de corte em pastagem de azevém sob pastejo contínuo, em razão das diferentes doses de nitrogênio.

Rev. Ceres, Viçosa, v. 58, n.3, p. 329-335, mai/jun, 2011 
de nitrogênio $(25,100,175,325 \mathrm{~kg}$ de $\mathrm{N} / \mathrm{ha})$ que aplicou no pasto de azevém.

As diferentes doses de $\mathrm{N}$ não influenciaram a taxa de bocado e o tempo de procura da estação dos cordeiros em pastejo. Os valores médios encontrados foram de 0,33 seg, 19 passos e 1,30 min para taxa de bocado, número de passos e tempo para 10 estações, respectivamente.

\section{CONCLUSÕES}

A adubação nitrogenada da pastagem de azevém alterou as atividades de pastejo e ócio, levando a maior ingestão de pasto pelos cordeiros com o aumento da dose de nitrogênio. Os cordeiros apresentaram hábito de pastejo concentrado ao amanhecer e ao entardecer. O estágio fenológico da pastagem foi determinante na duração das atividades de pastejo, ruminação e ócio dos ovinos, independentemente do nível de fertilização utilizada.

\section{REFERÊNCIAS}

Armstrong RH, Robertson E \& Hunter, EA (1995) The effect of sward height and its direction of change on the herbage intake, diet selection and performance of weaned lambs grazing ryegrass swards. Grass and Forage Science, 50:389-398.

Barthran GT \& Grant SA (1984) Defolation of ryegrass-dominated swards by sheep. Grass and Forage Science, 39:211-219.

Carvalho PCF (1997) A estrutura da pastagem e o comportamento ingestivo de ruminantes em pastejo. In: Jobim CC, Santos GT \& Cecato U (Eds.) Simpósio sobre avaliação de pastagens com animais, Maringá. 1:25-52.

Carvalho PCF, Ribeiro Filho H \& Poli CHEC (2001) Importância da estrutura da pastagem na ingestão e seleção de dietas pelo animal em pastejo. In: Reunião Anual da Sociedade Brasileira de Zootecnia, Piracicaba. Anais, SBZ. p.853-871.

Comissão de Fertilidade do Solo-RS/SC (1995) Recomendações de adubação e calagem para os Estados do Rio Grande do Sul e Santa Catarina. 3.ed. Passo Fundo, Sociedade Brasileira de Ciência do Solo/Embrapa-CNPT. 223p.

Empresa Brasileira de Pesquisa Agropecuária - EMBRAPA (1999) Centro Nacional de Pesquisa do Solo - CNPS. Sistema Brasileiro de Classificação de solos. Rio de Janeiro. 412p.

Forbes TDA \& Hodgson J (1985) Comparative studies of the influence of sward conditions on the ingestive behaviour of cows and sheep. Grass and Forage Science, 40:69-77.

Freitas TMS de (2003) Dinâmica da produção de forragem, comportamento ingestivo e produção de ovelhas Ile de France em pastagem de azevém anual (Lolium multiflorum Lam.) em resposta a doses de nitrogênio. Dissertação de Mestrado. Universidade Federal do Rio Grande do Sul, Porto Alegre. 114p.

Gibb M (1998) Animal grazing/intake terminology and definition. In: 3 Pasture Ecology And Animal Intake. Proceedings. Dublin. p.21-37.

Laca EA \& Lemaire G (2002) Measuring sward structure. In: T'mannetje L \& Jones RM (Eds.) Field and laboratory methods for grassland and animal production research. Wallingford, CAB International. p.103-122.

Mayes E \& Duncan P (1986) Temporal patterns of feeding behaviour in free-ranging horses. Behaaviour Leiden, 96:105129.
Medeiros RB, Pedroso CES \& Jornada JBJ (2007) Comportamento ingestivo de ovinos no período diurno em pastagem de azevém anual em diferentes estádios fenológicos. Revista Brasileira de Zootecnia, 36:198-204.

Moot GO \& Lucas HL (1952) The design conduct and interpretation of grazing trials on cultivated and improved pastures. In: 6 International Grassland Congress. Pensylvania: State College. Proceedings. p.380-1395.

Parente HN, Zanine AM \& Santos EM (2005) Habito de pastejo de caprinos da raça Saanen em pastagem de tifton 85 (Cynodon ssp). Revista da Faculdade de Zootecnia, Veterinária e Agronomia de Uruguaiana, 12:01-19.

Pedroso CES, Medeiros RB \& Silva MA (2004) Comportamento de Ovinos em Gestação e Lactação sob Pastejo em Diferentes Estádios Fenológicos de Azevém Anual. Revista Brasileira de Zootecnia, 33:1340-1344.

Pellegrini LG, Monteiro ALG, Neumann M, Moraes A, Pellegrin ACRS, Lustosa SBC (2010a) Produção e qualidade de azevémanual submetido a adubação nitrogenada sob pastejo por cordeiros. Revista Brasileira de Zootecnia, 39:1894-1904.

Pellegrini LG, Monteiro ALG, Neumann M, Moraes A, Bona Filho B, Molento MB, Pellegrin ACRS (2010b) Produção de cordeiros em pastejo contínuo de azevém anual submetido à adubação nitrogenada. Revista Ciência Rural, 40:1399-1404.

Poli CHEC, Monteiro ALG, Barros CS, Dittrich JR, Fernandes SR \& Carvalho PCF (2009) Comportamento ingestivo de cordeiros em três sistemas de produção em pastagem de Tifton 85 . Acta Scientiarum. Animal Sciences, 31:235-241.

Silveira EO (2001) Produção e comportamento ingestivo de cordeiros em pastagem de azevém anual (Lolium multiflorum lam.) Manejada em diferentes alturas. Dissertação de Mestrado. Universidade Federal do Rio Grande do Sul, Porto Alegre. 297p.

Statistical Analisys Systems-SAS. (1997) User's guide: statistics. Version 6, Cary. 1052p.

Stobbs TH (1975). The effect of plant structure on the intake of tropical pastures. III. Influence of fertilizer nitrogen on the size of bite harvested by Jersey cows grazing Setaria anceps cv. Kazungula swards. Australian Journal of Agriculturl Research, 26:997-1007.

Rev. Ceres, Viçosa, v. 58, n.3, p. 329-335, mai/jun, 2011 